\title{
Virtual Trial of Glycaemic Control Performance and Nursing Workload Assessment in Diabetic Critically Ill Patients
}

\author{
Athirah Abdul Razak ${ }^{1}$, Asma' Abu-Samah ${ }^{1}$, Normy Norfiza Razak ${ }^{1}$, Saliza Baharudin ${ }^{1}$, Fatanah Suhaimi $^{2}$, Ummu $^{2}$ \\ Jamaludin $^{3}$, Azrina Ralib ${ }^{4}$, Mohd Basri Mat-Nor ${ }^{4}$ \\ ${ }^{I}$ Institute of Engineering Infrastructure, College of Engineering, Universiti Tenaga Nasional, 43000, Kajang, Selangor, Malaysia \\ ${ }^{2}$ Advanced Medical and Dental Institute, USM, 13200, Bertam, Kepala Batas Penang, Malaysia \\ ${ }^{3}$ Human Energy Focus Group (HPEG), Universiti Malaysia Pahang, 26600, Pekan, Pahang, Malaysia \\ ${ }^{4}$ Department of Anesthesiology and Intensive Care, International Islamic University Malaysia, 25200, Kuantan, Pahang, Malaysia \\ *Corresponding author E-mail: athirahrazak@gmail.com
}

\begin{abstract}
Tight glycaemic control in critically ill patients is used to reduce mortality in intensive care units. However, its usage is debatable in reducing hypoglycaemia or accurately maintain normoglycaemia level. This paper presents the assessment for two 'wider' Stochastic TARgeted (STAR) glycemic controllers, namely Controller A (blood glucose (BG) target 4.4-8.0 mmol/L) and Controller B (BG target 4.4-10.0 $\mathrm{mmol} / \mathrm{L}$ ) with 1 to 3 hour nursing interventions. These controllers were assessed to determine the better control on diabetic and non-diabetic patients. 66 diabetic and 66 non-diabetic critically ill patient's data from Hospital Tunku Ampuan Afzan (HTAA) were employed for virtual trial simulations with a clinically validated physiological model. Performance metrics were assessed within the percentage time in band (TIB) of 4.4 to $8.0 \mathrm{mmol} / \mathrm{L}, 4.4$ to $10.0 \mathrm{mmol} / \mathrm{L}$, and 6.0 to $10.0 \mathrm{mmol} / \mathrm{L}$. Controller A shows better performance in normoglycaemic TIB of 4.4 to $10.0 \mathrm{mmol} / \mathrm{L}$ where non-diabetic and diabetic patients achieved $92.5 \%$ and $83.8 \%$ respectively. In conclusion, Controller A is higher in efficiency and safer to be used for both patients cohorts. However, higher clinical interventions in diabetic patients within this control raise the alarm to reduce nursing workload. This is believed to improve clinical interventions burnout and ensure patient's comfortability.
\end{abstract}

Keywords: Diabetes; Glycaemic Control; Model-Based Virtual Trial; STAR Protocol; Blood Glucose.

\section{Introduction}

Critically ill patients in the intensive care unit (ICU) are susceptible to stress hyperglycaemia with comorbidities like diabetes mellitus, sepsis, myocardial infarction, as well as a high mortality rate [1]. Hyperglycaemia is a condition where non-diabetic or diabetic patient's blood glucose (BG) level is higher than 10.0 $\mathrm{mmol} / \mathrm{L}$ [2], or when both types of patient have instantaneous BG measurement of $11.9 \mathrm{mmol} / \mathrm{L}$ [3]. In 2001, Van de Berghe et al., proposed to treat hyperglycaemia in ICU with tight glycaemic control (TGC) using control tight target range of 4.4 to 6.1 $\mathrm{mmol} / \mathrm{L}$ and the approach reduced mortality up to $40 \%$ [4]. Since then, most ICU opts to use TGC even though the target range of glucose control is still being debated over their resulting number of hypoglycaemia, longer period of stay and higher nursing workload [5], [6].

Different type of controls have been reported in many TGC studies [7], [8], and the preferred approach is the sliding-scale protocol [9]. Chase et al., Okabayashi et al., and Lin et al., proposed modelbased protocol with TGC studies as a solution to reduce mortality and hypoglycaemia events [10]-[12]. Most studies [10]-[15] tried to optimize glycaemic control performance in ICU patients but none have explicitly distinguished the treatment between the diabetic and non-diabetic patients. A study on the impact of a protocol between these two types of patients was done recently by Jamaludin et al., [16] on retrospective patients data, resulting in
$82 \%$ and $70.6 \%$ of BG levels were within normoglycaemic band for non-diabetic and diabetic cohort under Stochastic TARgeted (STAR) glycaemic control protocol.

The STAR protocol generates optimal patient-specific insulin and nutrition treatments that maximizes BG control and nutrition intake, while maintaining a maximum 5\% risk of hypoglycaemia (low blood sugar level) incidences [17]. Jamaludin et al. studies suggested a revision of the physiological ICING model used in the protocol to account for dysfunction of pancreatic function experienced by diabetic patients. The model's descriptions are presented in supporting information section. Secondly, their BG control assessment was applied to a wider and normal BG target range of 4.4 to $10 \mathrm{mmol} / \mathrm{L}$ and was found to introduce a high number of hypoglycemic episodes.

The STAR protocol has already been implemented in New Zealand [18], Hungary [19], [20] ICUs and latest in a Malaysian Hospital ICU, in the form of pilot study [21]. The latter focused mainly on the assessment of the protocol without discriminating the critically ill patients status. In Jamaludin et al., BG target was used as a benchmark on the same retrospective patients data from our previous study [22] but this time focus is on the protocol fit errors with tighter target range control of $4.4-8.0 \mathrm{mmol} / \mathrm{L}$ called Controller A in this paper. The study investigated BG fit errors between the two types of patients to see if the chosen physiological model efficacy has impact on the results. Results demonstrated very low fit errors for each type of patients and no significant difference between them. Simulation of STAR protocol on these patients and on the target control were shown to deliver real time 
model-based insulin therapy efficiently with low number of hypoglycemia incidences.

This paper digs deeper into the interrelationship between the two type of patients towards the use of STAR protocol by determining the control performance with 2 BG targets, Controller A (BG 4.4 to $8 \mathrm{mmol} / \mathrm{L}$ ) and [16] Controller B (BG 4.4 to $10.0 \mathrm{mmol} / \mathrm{L})$. Up to date, the interrelationship between diabetic status and BG target control has not been verified, whether wider BG used on diabetic patient may lead to higher efficiency which in results may lower nursing workload. Percentages of time in band (TIB) were compared to determine which glycaemic control performs better on diabetic patients. The TIBs and other metrics such as patient's safety, model protocol efficacy, and nursing workload interventions are assessed through a virtual trial method.

\section{Methodology}

Retropective data of 132 critically ill patients from Hospital Tunku Ampuan Afzan (HTAA), Malaysia treated with slidingscale insulin therapy in the ICU were used in this study. They were divided into equal cohorts of diabetic and non-diabetic patients with almost identical median and interquartile range [IQR] of age, weight and height. Their demographics per cohort can be referred to in Table 1.

Table 1: Patient's Demographic for HTAA

\begin{tabular}{|c|c|c|}
\hline Characteristics & Non-Diabetic & Diabetic \\
\hline Age (years) in & $55[34-62]$ & $58[50-67]$ \\
Median [IQR] & $24(36.3 \%)$ & $34(51.5 \%)$ \\
\hline Gender: & $42(63.7 \%)$ & $32(49.5 \%)$ \\
Female & $70[60-80]$ & $70[60-80]$ \\
Male & $161[157-168]$ & $160[153-166]$ \\
\hline Weight (kg) & 37 & 39 \\
in Median [IQR] & 20 & 20 \\
Height (cm) & 9 & 3 \\
in Median [IQR] & 0 & 1 \\
Category of patient: & 0 & 1 \\
Medical & 0 & $5[4-5.5]$ \\
Surgical & $5[3-5.5]$ & $36: 30: 0$ \\
\hline ENeuro & $42: 22: 2$ & \\
\hline Urology & & \\
Opthal & & \\
\hline LOS (days) & & \\
\hline Mortality (0:1:2)* & & \\
\hline
\end{tabular}

*0 for non-survivors, 1 for survivors and 2 for unknown.

Numbers of patients for Medical and Surgical ICU admission between cohorts are also similar. However, the percentage of patient's gender, number of admitted patients under ears, nose and throat (ENT), urology and ophthalmology were different. Actual patient's length of stay (LOS) signifies the treatment days of the patient's in the ICU. Minimum time of 12 hours on the day of ICU admission and discharged were considered as one day. Both cohorts have an average of 5 LOS days. Lastly, patients are classified under three groups of mortality namely as non-survivors, survivors and unknown. Both cohorts have high number of mortality (42 and 36 patients).

Once patient's demographics were identified, a dataset consisting of BG measurements $(\mathrm{mmol} / \mathrm{L})$, given insulin $(\mathrm{U} / \mathrm{hr})$ and given dextrose $(\mathrm{g} / \mathrm{hr})$ were extracted to start the assessment using a virtual trial framework [20], [23]. The trial is divided into two big steps, where the first step is virtual fitting to identify insulin sensitivity $\left(\mathrm{S}_{I}\right)$ profile from clinical data, a parameter that represents hourly metabolic rate for each patient. It was done using an integral fitting method [24]. $\mathrm{S}_{I}$ can capture patient specific blood glucose response to insulin and highly variable dynamic of insulin kinetics [25].

In the second step, both cohorts BG performance were then simulated using the generated $S_{I}$ profiles. MATLAB Software was used for the virtual simulation. The simulation uses Intensive Control
Insulin Nutrition Glucose (ICING) model [12] and $S_{I}$ profile to loop the STAR control algorithm by utilizing the current and previous reading of $\mathrm{BG}$, insulin and dextrose to propose next best insulin and dextrose recommendation based on chosen target range [12], [18]. Virtual simulation BG target for Controller A was set to $4.4-8.0 \mathrm{mmol} / \mathrm{L}$ following STAR protocol guidelines [18], while Controller B was set to $4.4-10.0 \mathrm{mmol} / \mathrm{L}$ [16], the range for normoglycaemia. The maximum insulin dose was capped at $9 \mathrm{U} / \mathrm{hr}$ for both BG controllers. Feed given was mostly enteral nutrition with goal dextrose rate between 30 to $100 \%$.

Performance of STAR protocol was captured through the percentage of BG measurements within time in band (TIB) over the total measurements. Nursing workload in this work was defined as the total number of glucometer reading, insulin administration and feed adjustment between 1-3 hours depending on nurse's decision for intervention. Execution practicality of the protocol was determined through nursing workload and patient safety where maximum risk must be below $5 \%$ for $\mathrm{BG}<4.0 \mathrm{mmol} / \mathrm{L}$ (mild hypoglycaemia) and $\mathrm{BG}<2.2 \mathrm{mmol} / \mathrm{L}$ (severe hypoglycaemia).

Median and interquartile range (IQR) of BG, insulin, feed, glucose rate, number of nursing workload, TIB $4.4-8.0 \mathrm{mmol} / \mathrm{L}$, TIB 4.4 - $10.0 \mathrm{mmol} / \mathrm{L}$, TIB $6.0-10.0 \mathrm{mmol} / \mathrm{L}, \% \mathrm{BG}>10.0$ $\mathrm{mmol} / \mathrm{L}, \% \mathrm{BG}<4.0 \mathrm{mmol} / \mathrm{L}$ and $\% \mathrm{BG}<2.0 \mathrm{mmol} / \mathrm{L}$ were virtually simulated using ICING model by incorporating STAR Protocol were then tabulated. Mann-Whitney test was chosen to quantify statistical significance of diabetic and non-diabetic cohort simulation results. This non-parametric test was chosen to test the difference between the two independent samples. The value for this test is significant if the p-values is less than 0.05 . This test was performed on 2 different $\mathrm{BG}$ controllers and presented in a quadrant cross-validation p-value analysis.

\section{Results and Discussion}

Table 2 shows the list of results from simulated glycaemic control performance in median and interquartile range [IQR] while Figure 1 shows the quadrant of Mann-Whitney significant comparison test between the simulations. The length of stay (LOS) totalled up to 15903.75 hours. Median nursing workload (NW) for diabetic patients was greater by 10 from non-diabetic patients for both BG controllers. The table shows median and [IQR] of nursing workload interventions for diabetic (35 [44-54]) and non-diabetic (45 [53-59]) patients which are significantly different by 0.00051 in Controller A. Virtual simulation for Controller B results show the median and [IQR] of nursing workload in diabetic (36 [28-45]) and non-diabetic (43 [38-51]) resulting in p-value of 0.00063 . The $\mathrm{BG}$ measurements for Controller A and B of diabetic patients are significantly different to non-diabetic patients with 0.00063 and 0.0013 respectively. This means that a higher nursing effort is needed in measuring BG for sliding scale method to ensure diabetic cohort has a manageable glycaemia.

Simulated median blood glucose (BG) levels and insulin doses for diabetic patients $(8.3 \mathrm{mmol} / \mathrm{L}$ and $7.0 \mathrm{u} / \mathrm{hr})$ are higher than nondiabetic patients $(7.4 \mathrm{mmol} / \mathrm{L}$ and $5.0 \mathrm{U} / \mathrm{hr})$ in Controller A. As for Controller $\mathrm{B}$, median of $\mathrm{BG}(8.6 \mathrm{mmol} / \mathrm{L})$ and insulin $(7.0$ $\mathrm{U} / \mathrm{hr}$ ) in diabetic patients is almost similar in reading to Controller $\mathrm{A}$, but significantly different with $\mathrm{p}$-value 0.00002 . Controller A shows the feed rate for diabetic patients $(2.9 \mathrm{~g} / \mathrm{hr})$ are much lower at $50^{\text {th }}$ percentile as compared to non-diabetic patients $(4.2 \mathrm{~g} / \mathrm{hr})$. At $75^{\text {th }}$ percentile, the difference between diabetic $(5.2 \mathrm{~g} / \mathrm{hr})$ and non- diabetic $(6.6 \mathrm{~g} / \mathrm{hr})$ are $1.4 \mathrm{~g} / \mathrm{hr}$. In Controller B the feed median increased by $2.1 \mathrm{~g} / \mathrm{hr}$ and $1 \mathrm{~g} / \mathrm{hr}$ in non-diabetic and diabetic patients respectively.

The median percentage of TIB $4.4-8.0 \mathrm{mmol} / \mathrm{L}$ and $4.4-10.0$ $\mathrm{mmol} / \mathrm{L}$ for diabetic patients for both controllers are higher with total difference of $20.4 \%$ and $30.1 \%$. Percentage TIB of $4.4-$ $10.0 \mathrm{mmol} / \mathrm{L}$ shows better performance in Controller A rather than Controller B for both non-diabetic $(92.5 \%$ versus $90.9 \%)$ and diabetic patients $(83.8 \%$ versus $82.3 \%)$. This suggested that, these 
patients are better controlled under Controller A with tighter BG range. In addition, the p-value test of TIB $4.4-8.0 \mathrm{mmol} / \mathrm{L}$ and TIB $4.4-10.0 \mathrm{mmol} / \mathrm{L}$ in Figure 1 (d) shows there are no significant difference between Controller A and B in non-diabetic patients. Meanwhile, Controller A percentage TIB of $6.0-10.0$ $\mathrm{mmol} / \mathrm{L}$ for non-diabetic cohort is lower with small difference in median and IQR. Overall, Controller A shows good performance in all three TIBs including for both cohorts patient safety limits. Figure 1 shows the Mann-Whitney test results in between two controllers and in between their diabetic status. Quadrant 1(a) is the Controller A results between Diabetic (D) and Non-Diabetic (ND). Quadrant 1(b) is the cross analysis between Controllers A \& B between Diabetic and Diabetic. Quadrant 1(c) shows the results of Controller B between Diabetic to Non-Diabetic. Lastly, Quadrant 1(d) shows the cross analysis of Controllers A \& B between Non-Diabetic and Non-Diabetic. The p-value analyses of BG were significant in Figure 1(a) and 1(b) but not in 1(c) and 1(d). The pvalue of Insulin (I) were only significant in 1(a) and 1(d). As for feed $(\mathrm{F})$, only Controller A (D-ND) and Controller B (D-ND) analyses were significant. All TIB $4.4-8.0 \mathrm{mmol} / \mathrm{L}$, and TIB 4.4 $-10.0 \mathrm{mmol} / \mathrm{L}$ all showed significant p-values except for in Figure 1(d). Other than in Figure 1(b), all TIB of $6.0-10.0 \mathrm{mmol} / \mathrm{L}$ analyses were significant. The measurement for $\mathrm{BG}<4.0 \mathrm{mmol} / \mathrm{L}$ and $\mathrm{BG}<2.2 \mathrm{mmol} / \mathrm{L}$ are not statistically significant except for in Figure 1(d).

Table 2: Virtual simulations

\begin{tabular}{|c|c|c|c|c|}
\hline \multirow{2}{*}{$\begin{array}{c}\text { Simulation } \\
\text { Test } \\
\text { (Median } \\
\text { [IQR]) } \\
\end{array}$} & \multicolumn{2}{|c|}{ Protocol Controller A } & \multicolumn{2}{|c|}{ Protocol Controller B } \\
\hline & $\begin{array}{c}\text { Non- } \\
\text { Diabetic }\end{array}$ & Diabetic & $\begin{array}{c}\text { Non- } \\
\text { Diabetic }\end{array}$ & Diabetic \\
\hline $\mathrm{BG}(\mathrm{mmol} / \mathrm{L})$ & $\begin{array}{l}7.4[5.9- \\
9.1]\end{array}$ & $\begin{array}{l}8.3[6.5- \\
10.1]\end{array}$ & $\begin{array}{l}7.3[5.8- \\
9.6]\end{array}$ & $\begin{array}{l}8.6[6.3- \\
10.7]\end{array}$ \\
\hline Insulin (u/hr) & $\begin{array}{l}5.0[2.0- \\
8.0]\end{array}$ & $\begin{array}{l}7.0[3.5- \\
8.0]\end{array}$ & $\begin{array}{l}5.0[2.0- \\
8.0]\end{array}$ & $\begin{array}{l}7.0[3.5- \\
8.0]\end{array}$ \\
\hline Feed $(\mathrm{g} / \mathrm{hr})$ & $\begin{array}{l}4.2[1.9- \\
6.6]\end{array}$ & $\begin{array}{l}2.9[1.9- \\
5.2]\end{array}$ & $\begin{array}{l}6.3[2.3- \\
6.6]\end{array}$ & $\begin{array}{l}3.9[1.9- \\
6.6]\end{array}$ \\
\hline $\begin{array}{l}\text { Glucose rate } \\
\text { (\% goal) }\end{array}$ & $\begin{array}{l}64.6[29.8- \\
100.6]\end{array}$ & $\begin{array}{l}44.7[29.8- \\
79.5]\end{array}$ & $\begin{array}{l}95.6[34.8- \\
100.6]\end{array}$ & $\begin{array}{l}59.6[29.8 \\
-100.6] \\
\end{array}$ \\
\hline $\mathrm{S}_{I}(\mathrm{~L} / \mathrm{mU} \cdot \mathrm{min})$ & $\begin{array}{l}0.25 \mathrm{e}^{-3} \\
{[0.16-0.34]}\end{array}$ & $\begin{array}{l}0.15 \mathrm{e}^{-3} \\
{[0.08-0.22]}\end{array}$ & $\begin{array}{l}0.25 \mathrm{e}^{-3} \\
{[0.16-0.34]}\end{array}$ & $\begin{array}{l}0.15 \mathrm{e}^{-3} \\
{[0.08-} \\
0.22]\end{array}$ \\
\hline $\begin{array}{l}\text { Number of } \\
\text { Nursing } \\
\text { Workload }\end{array}$ & 35 [44-54] & $45[53-59]$ & 36 [28-45] & $\begin{array}{l}43[38- \\
51]\end{array}$ \\
\hline $\begin{array}{l}\text { Number of } \\
\text { BG measure- } \\
\text { ment }\end{array}$ & 4433 & 5383 & 3890 & 4571 \\
\hline \multicolumn{5}{|c|}{ (Interpolated) Hourly Resampled Statistics } \\
\hline $\begin{array}{l}\text { Time in target } \\
\text { band } \% \mathrm{BG} \\
(4.4-8.0 \\
\mathrm{mmol} / \mathrm{L})\end{array}$ & $\begin{array}{l}81.6 \text { [61.1 - } \\
90.3]\end{array}$ & $\begin{array}{l}62.9[43.1- \\
73.6]\end{array}$ & $\begin{array}{l}75.5 \text { [52.1 - } \\
88.3]\end{array}$ & $\begin{array}{l}52.2[33.8 \\
-72.0]\end{array}$ \\
\hline $\begin{array}{l}\text { Time in target } \\
\text { band } \% \mathrm{BG} \\
(4.4-10.0 \\
\mathrm{mmol} / \mathrm{L})\end{array}$ & $\begin{array}{l}92.5[83.1- \\
96.1]\end{array}$ & $\begin{array}{l}83.8[73.8- \\
91.4]\end{array}$ & $\begin{array}{l}90.9[83.2- \\
95.8]\end{array}$ & $\begin{array}{l}82.3[68.8 \\
-90.4]\end{array}$ \\
\hline $\begin{array}{l}\text { Time in target } \\
\text { band } \% \mathrm{BG} \\
(6.0-10.0 \\
\mathrm{mmol} / \mathrm{L})\end{array}$ & $\begin{array}{l}58.3[50.0- \\
66.7]\end{array}$ & $\begin{array}{l}61.6[48.6- \\
70.8]\end{array}$ & $\begin{array}{l}61.3[49.3- \\
68.7]\end{array}$ & $\begin{array}{l}58.9[51.4 \\
-68.8]\end{array}$ \\
\hline $\begin{array}{l}\% \mathrm{BG}(>10.0 \\
\mathrm{mmol} / \mathrm{L})\end{array}$ & $\begin{array}{l}4.0[2.1- \\
13.7]\end{array}$ & $\begin{array}{l}14.5[5.3- \\
24.1]\end{array}$ & $\begin{array}{l}4.9[2.1- \\
14.1]\end{array}$ & $\begin{array}{l}16.5[6.2- \\
30.7]\end{array}$ \\
\hline $\begin{array}{l}\% \mathrm{BG}(<4.0 \\
\mathrm{mmol} / \mathrm{L})\end{array}$ & $\begin{array}{l}0.0[0.0- \\
1.3]\end{array}$ & $\begin{array}{l}0.0[0.0- \\
1.6]\end{array}$ & $\begin{array}{l}0.0[0.0- \\
1.4]\end{array}$ & $\begin{array}{l}0.0[0.0- \\
1.4]\end{array}$ \\
\hline $\begin{array}{l}\% \mathrm{BG}(<2.0 \\
\mathrm{mmol} / \mathrm{L})\end{array}$ & $\begin{array}{l}0.0[0.0- \\
0.0]\end{array}$ & $\begin{array}{l}0.0[0.0- \\
0.0]\end{array}$ & $\begin{array}{l}0.0[0.0- \\
0.0]\end{array}$ & $\begin{array}{l}0.0[0.0- \\
0.0]\end{array}$ \\
\hline
\end{tabular}

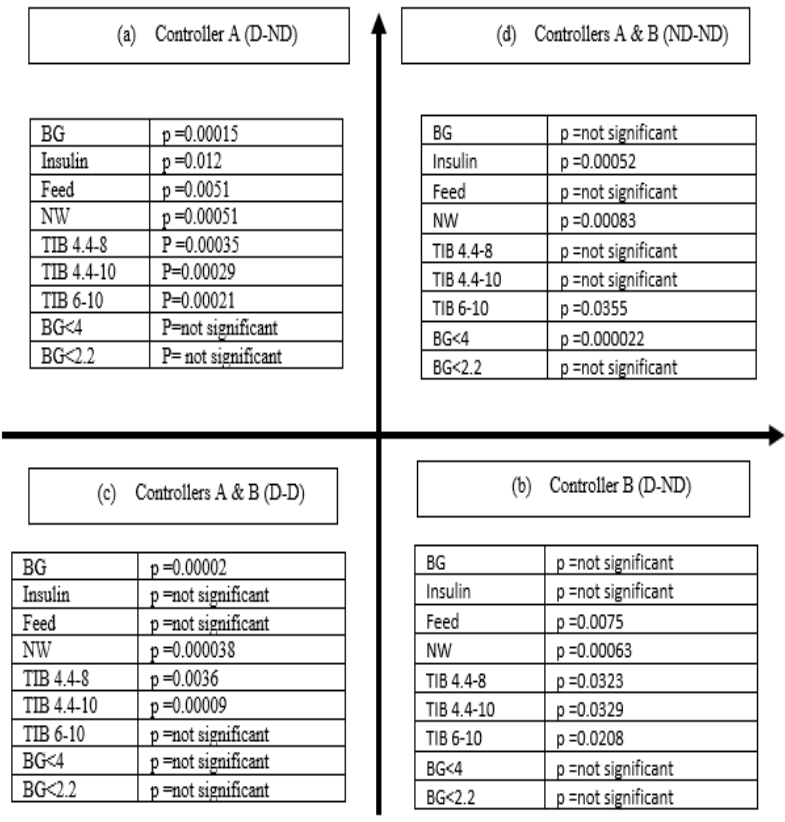

Fig. 1: Quad p-value analysis of Controller A and Controller B. (a) The analyses of Controller A between Diabetic (D) to Non-Diabetic (ND). (b) The analyses of Controllers A \& B between D and D. (c) The analyses of Controller B between D to ND. (d) The analyses of Controllers A \& B between ND and ND.

Figure 2(a) shows an example of patient's profile for a nondiabetic patient with 76 hours of stays while Figure 2(b) shows patient's profile of a diabetic patient with 140 hours of stay. From top to bottom, the first panel shows the real and simulated BG measurements. The second panel shows simulated plasma insulin (I) and interstitial insulin (Q), the third panel shows insulin sensitivity $\left(\mathrm{S}_{I}\right)$ which represents the hourly dynamic metabolic rate, and the last panel shows the provided insulin and enteral (EN) and parenteral (PN) dextrose. The $S_{I}$ profile for Figure 2 (b) is more dynamic and the given insulin as well as feed rate were higher for non-diabetic patient in Figure 2 (a). The more stable $S_{I}$ for nondiabetic patient indicates that this particular patient was under better glycaemic control with STAR protocol and ICING model.
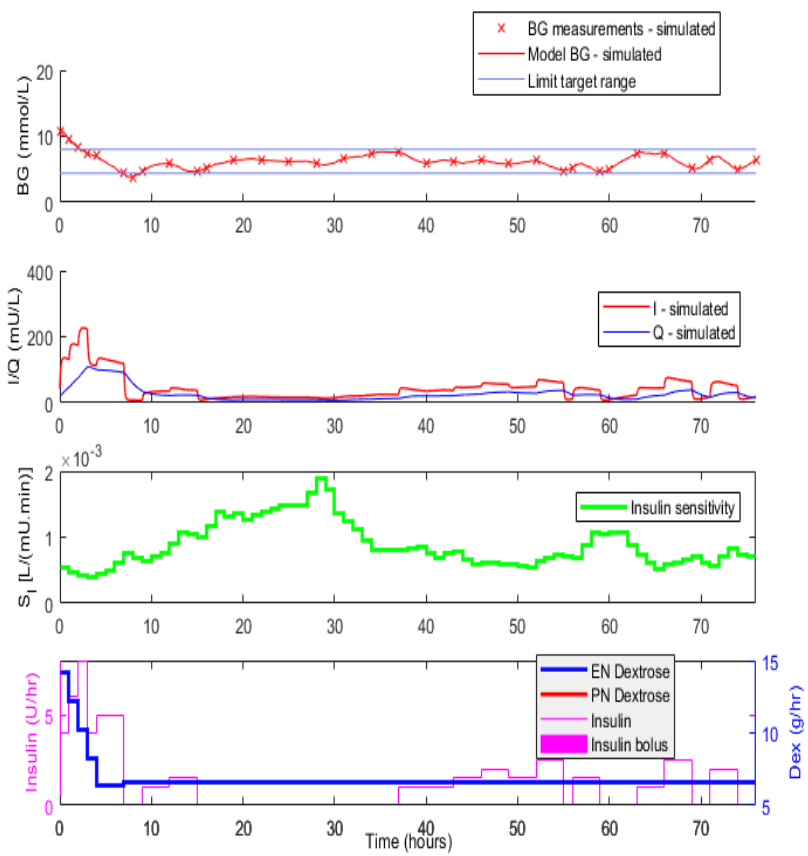

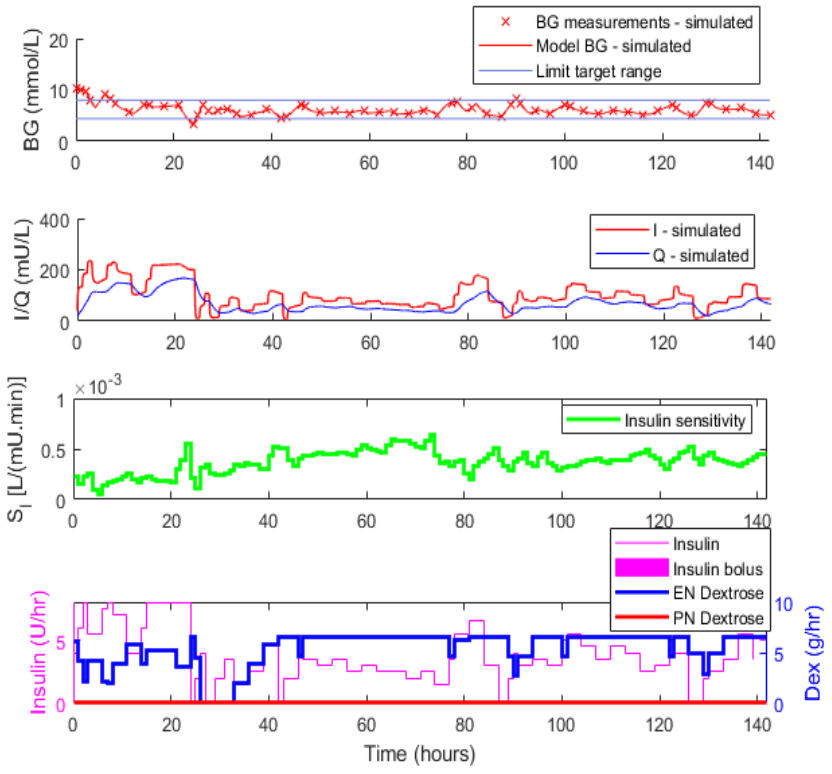

1 (b)

Fig. 2: Patient's profile of (a) Non-diabetic and (b) Diabetic patients in the ICU. First panels show the blood glucose (BG) $[\mathrm{mmol} / \mathrm{L}]$ clinical data (cross), BG fitted data (red line) and BG limit of 4.4 to 8.0 (blue lines). The second panels show the simulated plasma insulin (straight line) and the interstitial insulin (dotted line). The third panels and the last panel shows the recommended insulin (pink line) and enteral (EN) and parenteral (PN) feed (blue and red lines).

Figure 3 shows the two cohorts' cumulative distribution frequency (CDF) of median blood glucose level on two controllers. This figure illustrates the CDF percentile in the y-axis versus the median $\mathrm{BG}$ reading in the $\mathrm{x}$-axis. This result shows an important gap in median blood glucose reading between the two cohorts with glycaemic control using STAR protocol. Blood glucose reading in diabetic and non-diabetic patients at $75^{\text {th }}$ percentile shows the median BG is within the boundary of $8.0-10.0 \mathrm{mmol} / \mathrm{L}$. Diabetic patients CDF for both controllers is less tight but at $75^{\text {th }}$ percentile, the median BG target was less than $10.0 \mathrm{mmol} / \mathrm{L}$. The surpassed BG was still acceptable because through insulin infusion, BG reading was still under control. Most importantly, Figure 3 shows no episodes of hypoglycaemia.

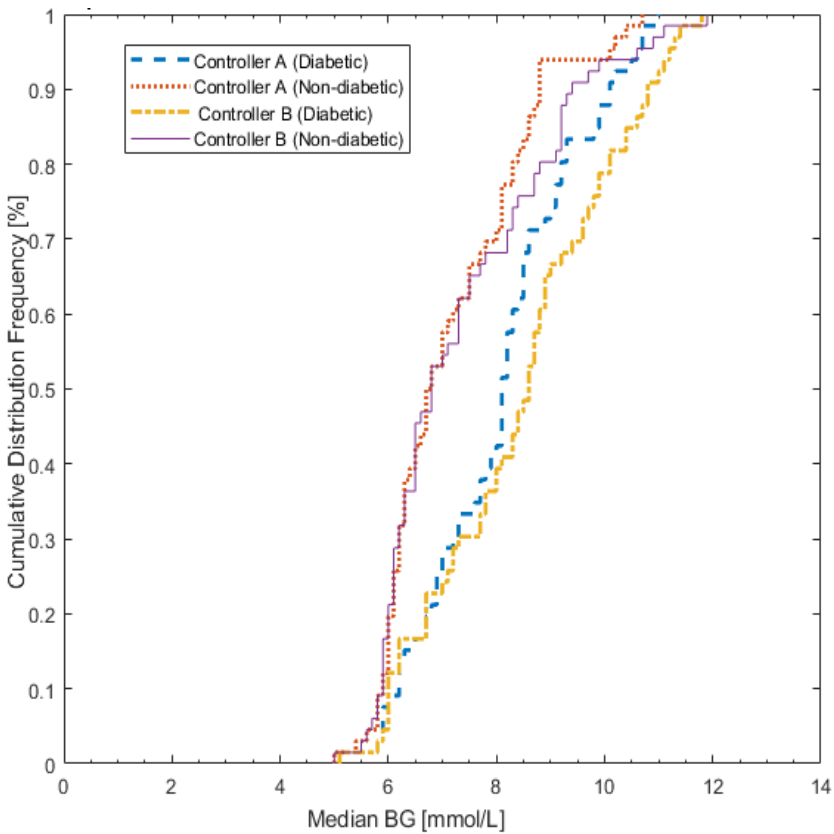

Fig. 3: Cumulative Distribution Frequency (CDF) of Controller A and Controller B versus Median BG for non-diabetic and diabetic cohorts.
This paper studied which glycaemic target controller is better in performance by assessing the percentage of glycaemic time in band (TIB). Based on the simulation of Controller A results, the percentage TIB within $4.4-8.0 \mathrm{mmol} / \mathrm{L}$ for diabetic and nondiabetic cohorts achieved $62.9 \%$ and $81.6 \%$ where as for Controller B, the TIBs are significantly lower at $52.2 \%$ and $75.5 \%$ respectively. Similarly, for TIB of $4.4-10 \mathrm{mmol} / \mathrm{L}$ results, Controller A percentages are higher for both diabetic and non-diabetic. The third assessment, the TIB within $6.0-10.0 \mathrm{mmol} / \mathrm{L}$ for Controller A shows diabetic cohorts is higher than non-diabetic with $61.6 \%$ over $58.3 \%$. The performances in this paper show that Controller A (BG target of $4.4-8.0 \mathrm{mmol} / \mathrm{L}$ ) performs better towards diabetic patients rather than Controller B (BG target control $4.4-10.0$ $\mathrm{mmol} / \mathrm{L}$ ).

For insulin administration, there is significant difference in Quadrant 1(a) and 1(d) and the feed given are significant in Quadrant 1(a) and 1(c). This suggested that the clinical insulin interventions for diabetic patients did not change in insulin administration and the feed only increased by $+1 \mathrm{~g} / \mathrm{hr}$ despite differences in BG target control. The amount of insulin infusion and feed given were automatically recommended in STAR protocol which are within the range of 2 to $9 \mathrm{U} / \mathrm{hr}$ and 30 to $100 \%$ targeted glucose rate respectively. This is because diabetic patients cannot depend on endogenous insulin secretion as their pancreas is unable to secrete sufficient insulin to normalize blood glucose level. Thus the requirement of external insulin either by infusion or bolus. The feed given were within 1.9 to $6.6 \mathrm{~g} / \mathrm{hr}$. Insulin administration was slightly higher and feed given was almost similar to Christchurch Hospital [26]. From these virtual trial results, patient immediate response can either be from insulin alone or combination of insulin and feed [18].

One advantage of ICING model and STAR protocol using the chosen target ranges, was the absence of severe hypoglycaemia episodes which provides good patient safety. Table 2 shows simulation results percentage of $\mathrm{BG}<4.0 \mathrm{mmol} / \mathrm{L}$ (mild hypoglycaemia) for both glycaemic target control are less than $2.0 \%$ at $75^{\text {th }}$ percentile for diabetic and non-diabetic patients, which is less than $5 \%$ maximum risk as expected with STAR protocol. Based on Figure 2, both groups attained normoglycaemic level after an average of 10 hours under STAR treatment. If we zoomed into the BG performance, median CDF plots for both cohorts were within the range below $10 \mathrm{mmol} / \mathrm{L}$ at $75^{\text {th }}$ percentile.

Controller A nursing workload for diabetic and non-diabetic patients was significantly different to Controller B and lower by $\mathrm{p}$ value $=0.00051$ and $\mathrm{p}$-value $=0.000063$ if compared to Controller B. Even though the total nursing workload was higher for diabetic patients, this number of clinical interventions were expected as diabetic patient or critical care patients required more attention in the intensive care unit compared to patient without diabetes [27]. Further comparative studies need to be conducted with the data coming from the conventional approach in Malaysia ICU, namely the sliding scale approach to understand the difference of nursing workload in both diabetic and non-diabetic patients.

Finally, the study was conducted with retrospective patients data receiving only insulin infusion treatment. Despite STAR protocol ability to recommend insulin in bolus form, any conclusion cannot be made regarding STAR protocol's ability in this aspect to further reducing nursing workload, as insulin bolus requires less nurse's intervention to modify the titrate. This can be done if more patients data with such treatment can be obtained.

\section{Conclusion}

In conclusion, this paper assessed STAR protocol virtual simulations on HTAA patient demonstrated good performance of Controller A rather than less tight BG of Controller B. Nursing workload was also assessed, confirming the need for improvements in future for less clinical intervention in diabetic patients. In the 
meantime, generalizing the protocol performance in different clinical setting for diabetic cohorts will be our next work target.

\section{Acknowledgement}

Thank you to Universiti Tenaga Nasional and Ministry of Higher Education (MOHE) for funding our research with UNITEN Internal Grant (UNIIG) and FRGS 2015 respectively, to International Islamic University Malaysia for the provision of data, and to Universiti Malaysia Pahang and Universiti Sains Malaysia for research collaborations.

\section{References}

[1] L. J. Silva-Perez, M. A. Benitez-Lopez, J. Varon, and S. Surani, (2017) "Management of critically ill patients with diabetes," World J. Diabetes, vol. 8, no. 3, p. 89.

[2] J. S. Krinsley, P. Maurer, S. Holewinski, R. Hayes, D. McComsey, G. E. Umpierrez, and S. A. Nasraway, (2017) "Glucose Control, Diabetes Status, and Mortality in Critically Ill Patients: The Continuum From Intensive Care Unit Admission to Hospital Discharge," Mayo Clin. Proc., vol. 92, no. 7, pp. 1019-1029.

[3] American Diabetes Association, "Classification and Diagnosis of Diabetes, (2017)" Diabetes Care, vol. 40, no. Supplement 1, pp. S11-S24.

[4] G. Van den Berghe, P. Wouters, F. Weekers, C. Verwaest, F Bruyninckx, M. Schetz, D. Vlasselaers, P. Ferdinande, P. Lauwers, R. Bouillon, W. Van Den Berghe, Greet Pieter, F. Weekers, C. Verwaest, F. Bruyninckx, M. Schetz, D. Vlasselaers, P. Ferdinande, P. Lauwers, and R. Bouillon, (2001) "Intensive Insulin Therapy in Critically Ill Patients,” N. Engl. J. Med., vol. 345, no. 19, pp. 1359 1367.

[5] F. Suhaimi, A. Le Compte, J.-C. Preiser, G. M. Shaw, P. Massion, R. Radermecker, C. G. Pretty, J. Lin, T. and Desaive, and J. G. Chase, (2010) "What Makes Tight Glycemic Control Tight? The Impact of Variability and Nutrition in Two Clinical Studies," J. Diabetes Sci. Technol., vol. 4, no. 2010, pp. 284-298.

[6] M. A. Malesker, P. A. Foral, A. C. McPhillips, K. J. Christensen, A Julie A. Chang, and D. E. Hilleman, (2007) "An Efficiency Evaluation of Protocols for Tight Glycaemic Control in Intensive Care Units," Am. J. Crit. Care, vol. 16, no. 6, pp. 589-598.

[7] J. S. Krinsley and J.-C. Preiser, (2015) "Time in blood glucose range 70 to $140 \mathrm{mg} / \mathrm{dl} \& \mathrm{gt} ; 80 \%$ is strongly associated with increased survival in non-diabetic critically ill adults," Crit. Care, vol. 19 , no. 1 , p. 179.

[8] J.-C. Preiser, (2009) "NICE-SUGAR: the end of a sweet dream?," Crit. Care, vol. 13, no. 3, p. 143.

[9] H. Zaman Huri, V. Permalu, and S. R. Vethakkan, (2014) "Slidingscale versus basal-bolus insulin in the management of severe or acute hyperglycemia in type 2 diabetes patients: a retrospective study.," PLoS One, vol. 9, no. 9, p. e106505.

[10] J. G. Chase, G. M. Shaw, T. Lotz, A. Lecompte, J. Wong, J. Lin, T. Lonergan, M. Willacy, and C. E. Hann, (2007) "Model-based Insulin and Nutrition Administration for Tight Glycaemic Control in Critical Care," Curr. Drug Deliv., vol. 4, no. 4, pp. 283-296.

[11] K. Okabayashi, T., Nishimori, I., Maeda, H., Yamashita, K., Yatabe, T. and Hanazaki, (2009) "Effect of Intensive Insulin Therapy Using a Closed-Loop Glycemic Control System in Hepatic Resection Patients A prospective randomized clinical trial.," Diabetes Care, vol. 32 , no. 8 .

[12] J. Lin, N. N. Razak, C. G. Pretty, A. Le Compte, P. Docherty, J. D. Parente, G. M. Shaw, C. E. Hann, and J. Geoffrey Chase, (2011) "A physiological Intensive Control Insulin-Nutrition-Glucose (ICING) model validated in critically ill patients," Comput. Methods Programs Biomed., vol. 102, no. 2, pp. 192-205.

[13] S. Schmidt, D. Boiroux, A. K. Duun-Henriksen, L. Frøssing, O. Skyggebjerg, J. B. Jørgensen, N. K. Poulsen, H. Madsen, S. Madsbad, and K. Nørgaard, (2013) "Model-based closed-loop glucose control in type 1 diabetes: the DiaCon experience.," J. Diabetes Sci. Technol., vol. 7, no. 5, pp. 1255-64.

[14] W. Alam, N. Ali, S. Ahmad, and J. Iqbal, (2018) "Super twisting control algorithm for blood glucose regulation in type 1 diabetes patients," Proc. 2018 15th Int. Bhurban Conf. Appl. Sci. Technol. IBCAST 2018, vol. 2018-Janua, no. January, pp. 1-7.

[15] I. C. R. Crosara, C. Mélot, and J.-C. Preiser, (2015) “A J-shaped relationship between caloric intake and survival in critically ill patients," Ann. Intensive Care, vol. 5, no. 1, p. 37.

[16] U. K. Jamaludin, F. Dzaharudin, and N. N. A. Razak, (2016) "Performance of STAR Virtual Trials for Diabetic and NonDiabetic in HTAA Intensive Care Unit," IEEE EMBS Conf. Biomed. Eng. Sci., pp. 193-198.

[17] L. M. Fisk, A. J. Le Compte, G. M. Shaw, S. Penning, T. Desaive, and J. G. Chase, (2012) "STAR development and protocol comparison,” IEEE Trans. Biomed. Eng., vol. 59, pp. 3357-3364.

[18] A. Evans, A. Le Compte, C.-S. S. Tan, L. Ward, J. Steel, C. G. Pretty, S. Penning, F. Suhaimi, G. M. Shaw, T. Desaive, and J. G. Chase, (2012) "Stochastic targeted (STAR) glycemic control: design, safety, and performance.," J. Diabetes Sci. Technol., vol. 6, no. 1, pp. 102-15,

[19] K. Stewart, C. G. Pretty, F. Thomas, G. M. Shaw, T. Desaive, B. Benyo, J. Homlok, A. Illyes, N. S. Nemedi, and J. G. Chase, (2016) "Generalizability of a Nonlinear Model-based Glycemic Controller," IFAC-PapersOnLine, vol. 49, no. 5, pp. 212-217.

[20] J. L. Dickson, K. W. Stewart, C. G. Pretty, M. Flechet, T. Desaive, S. Penning, B. C. Lambermont, B. Benyó, M. Shaw, and J. G. Chase, (2017) "Generalisability of a Virtual Trials Method for Glycaemic Control in Intensive Care," IEEE Trans. Biomed. Eng., vol. 9294, no. c, pp.1-18.

[21] A. Abu-Samah, N. H. Ahamad, N. N. Razak, F. M. Suhaimi, U. K. Jamaluddin, A. M. Ralib, M. B. Mat-Nor, C. G. Pretty, J. L. Dickson, and G. Chase, (2018) "Model-Based Insulin-Nutrition Administration for Glycemic Control in Malaysian Critical Care: First Pilot Trial," in 2nd International Conference for Innovation in Biomedical Engineering and Life Sciences: ICIBEL 2017 (in conjunction with APCMBE 2017), pp. 189-196.

[22] A. Abdul Razak, A. Abu-Samah, N. N. Razak, N. Ahamad, F. M. Suhaimi, U. K. Jamaludin, A. Md Ralib, and M. B. Mat-Nor, (2018) "Investigation of glucose-insulin model efficacy for diabetes patient in the ICU," in IFMBE Proceedings, vol. 67, pp. 177-181.

[23] J. G. Chase, F. Suhaimi, S. Penning, J.-C. Preiser, A. J. Le Compte, J. Lin, C. G. Pretty, G. M. Shaw, K. T. Moorhead, and T. Desaive, (2010) "Validation of a model-based virtual trials method for tight glycemic control in intensive care.," Biomed. Eng. Online, vol. 9 , no. 1, p. 84.

[24] C. E. Hann, J. G. Chase, J. Lin, T. Lotz, C. V Doran, and G. M. Shaw, (2005) "Integral-based parameter identification for long-term dynamic verification of a glucose-insulin system model.," Comput. Methods Programs Biomed., vol. 77, no. 3, pp. 259-70.

[25] A. A. Razak, N. N. Razak, F. M. Suhaimi, and U. Jamaluddin, (2014) "Efficacy of Glucose-Insulin Model for Sepsis Patients," vol. 00 , pp. 1-5.

[26] K. W. Stewart, C. G. Pretty, H. Tomlinson, F. L. Thomas, J. Homlok, S. N. Noémi, A. Illyés, G. M. Shaw, B. Benyó, and J. G. Chase,(2016) "Safety, efficacy and clinical generalization of the STAR protocol: a retrospective analysis," Ann. Intensive Care, vol. 6 , no. 1 .

[27] H. Thabit and R. Hovorka, (2014) "Glucose control in noncritically ill inpatients with diabetes: Towards closed-loop," Diabetes, Obes. Metab., vol. 16, no. 6, pp. 500-509. 